\title{
Analyzes of health profiles of patients receiving home health care services over last five years in Diyarbakir, Turkey
}

\author{
Rojan Gumus*1, Seyfettin Sarıbaș \\ ${ }^{1}$ Atatürk Health Vocational School, Dicle University, Turkey \\ ${ }^{2}$ Directorate of Public Health, Turkey
}

Received: August 9, 2016

DOI: $10.5430 /$ jha.v5n6p69
Accepted: September 23, $2016 \quad$ Online Published: October 11, 2016

URL: http://dx.doi.org/10.5430/jha.v5n6p69

\begin{abstract}
Objective: To determine the health profiles of patients who have been delivered home health care services by public hospitals in over the last five years.

Methods: Data which were recorded by the Ministry of Health and the Diyarbakir Directorate of Health Services had been provided from 1,826 patients from three city center and five district hospitals located in Diyarbakir, Turkey.

Results: Of 1,826 patients, 989 (54\%) were female and 837 (46\%) were male. The patients were divided into three age groups: 0-18 years $467(25 \%), 19-64$ years $511(28 \%)$ and +65 years $848(47 \%)$. There were more female patients in +65 age group and male in 0 -18 age group $\left(\chi^{2}=89.923, p<.001\right)$. In 2015, there was an increase in the number of people who received services in all age groups $\left(\chi^{2}=164.344, p<.001\right)$. It was found that neurodegenerative diseases were more widespread in +65 age group $\left(\chi^{2}=44.823, p<.001\right)$. Neurogenetic dieases were more seen in the $0-18$ age group $\left(\chi^{2}=97.800, p<.001\right)$. In the +65 age group, musculoskeletal $\left(\chi^{2}=16.037, p<.001\right)$ and respiratory diseases $\left(\chi^{2}=6.054, p<.05\right)$ were detected to be more widespread. There were no significant sex-based differences between the years involved $\left(\chi^{2}=2.246, p>.05\right)$. Neurodegenerative diseases $\left(\chi^{2}=4.07, p<.05\right)$, neurogenetic diseases $\left(\chi^{2}=6.043, p<.05\right)$ and respiratory diseases $\left(\chi^{2}=5.254, p<.05\right)$ were determined to be more widespread in male patients. Musculoskeletal $\left(\chi^{2}=17.943, p<.001\right)$ and cardiovascular diseases $\left(\chi^{2}=11.994\right.$, $p<.001)$ were seen more in female groups.

Conclusions: Over the last five years, there has been an increase in the utilization of home health care services. Policy legislation for health care services to be provided at home is generating succesful results.
\end{abstract}

Key Words: Home health care, Age groups, Public hospitals, Chronic diseases, Turkey

\section{INTRODUCTION}

Home health care services include a very comprehensive list of services such as medical, social services, physical therapy, nursing care, and speech-language therapy. ${ }^{[1]}$ It also covers a wide combination of different kinds of functions such as catheter care, administering injections, conducting psychological assessments, wound care, disease education, oxygen therapy, medication reminders, pain management, and nutritional evaluation. These services are conducted by skilled professionals such as medical practitioners, nurses, physical therapists, or home health aides who generally work for private home health care agencies, municipalities, and

*Correspondence: Rojan Gumus; Email: gumusrojan@gmail.com; Address: Atatürk Health Vocational School, Dicle University, Turkey. 
public institutions to help patients live with a greater degree of independence, assist the patient to continue to live at home, and improve the patient's health. ${ }^{[2,3]}$ Sometimes this care is proposed by physicians, but generally it is requested by family members or the patients themselves. ${ }^{[1,4]}$

Home health care services can save cost in addition to improving the comfort of patients. Since the 1990s, home-based health care has grown regularly in developed countries and has become very important. However, in Turkey, the issue was not seriously addressed by the government until 2010 In Turkey, all health services are provided by public and private sectors. Public health services are under the auspices of the Ministry of Health and implemented by the Social Security Institution (SSI). After the transformation of health programs, private sectors also began to provide home health services. As the Ministry of Health is the main provider of primary and secondary health care, it is responsible for health services and health policies in the country, including amendments for home health care services. The most serious regulation was made by Law 2551 in March 2005 and published in the Official Newspaper. ${ }^{[5]}$ This regulation provided the first official definition regarding the deliverance of home health care services. Next came Directive 3895, "The Implementation of Health Care Services at Home" in February 2010 that detailed all kinds of home care services, responsible staff, necessary material, and tools as stated by the Ministry of Health. ${ }^{[6]}$

After 2010, it was compulsory for public hospitals to provide home health care services leading to an expansion of utilization of home health care services by patients in need. In Diyarbakır, Turkey, between 2010 and 2013, these services were provided by the Diyarbakir Directorate of Health Services. Since 2013, the Secretary General of the Association of the Public Hospitals has been charged with providing home health care services. The Coordination Center of Home Health Care Services was founded in the greater Diyarbakir Public Health Center in order to coordinate the services. Three hospitals in the city center and five in other districts of Diyarbakır are connected to this center. Six medical practitioners, twenty-one nurses, and twenty-seven other skilled staff work at this center.

The literature highlights that some diagnoses are common among patients receiving home health care. Disabilities related to neurodegenerative disorders, neurogenetic disorders: brain injury, muskuloskeletal disorders, cardiovascular diseases, respiratory diseases and other chronic diseases such as diabetes, cancer, obstetric diseases are most studied diseases by researchers. ${ }^{[7-11]}$ In this study the referred diseases were taken into account in order to make a classification for those diseases seen most commonly among patients who delivered home health care services.

The subject of this study is to investigate the home health care services provided by the Diyarbakır Directorate of Health Service and the Secretary General of the Association of the Public Hospitals between 2010 and 2015 in Diyarbakir, Turkey. The necessary data were obtained from the Ministry of Health and the Diyarbakir Directorate of Health Service.

\section{MATERIALS AND METHODS}

In the present study, home health care services provided by the Diyarbakir Directorate of Health Services and the Secretary General of the Association of Public Hospitals from 2010-2015 were reviewed. Data were obtained over a 6-month period from the Ministry of Health and the Diyarbakır Directorate of Health Services, after obtaining formal permission. Ethics committee approval was obtained from Dicle University Hospital on the request of the Ministry of Health, which lasted for an additional 3 months.

First, tha data for 1,826 individuals who benefitted from home health care services between 2010-2015 in the city center and five districts of Diyarbakir were obtained. The patients were divided into three age groups (0-18, 19-64 and $65+$ years) and compared by sex, most common diseases, hospitals, and years. Descriptive statistics were calculated and chi-square tests were performed, using SPSS Version 21. A wide range of diseases was recorded by health staff; diseases were classified into six groups for the present analysis. The six diseases groups were:

(1) Disabilities related to neurodegenerative disorders (alzheimer, dementia, Parkinson's disease, multiple sclerosis, stroke, hydrocephalus, encephalitis, epilepsy, degenerative nerve diseases, amyotrophic lateral sclerosis [ALS], Huntington's disease, paraplegia)

(2) Disabilities related to neurogenetic disorders (ataxia, familial alzheimer, familial dementia, familial epilepsy, familial ALS, familial parkinsonian disease, fragile $\mathrm{X}$ syndrome, autism, down syndrome, genetic brain disorders, hereditary spastic paraplegia)

(3) Cardiovascular diseases (hypertension, heart diseases, high cholesterol)

(4) Musculoskeletal diseases (fractures, rheumatoid arthritis, postmenopausal and post-traumatic osteoperosis, clubfoot, hip dysplasia, orthopedic trauma, fractures, muscular dystrophy and scoliosis)

(5) Respiratory diseases (asthma, chronic bronchitis)

(6) Other diseases (diabetes, cancer, mental diseases, eye diseases) 


\section{RESULTS}

Of 1,826 patients, 989 (54\%) were female and $837(46 \%)$ were male. The patients were divided into three age groups: 0-18 years $467(25 \%), 19-64$ years $511(28 \%)$ and +65 years
$848(47 \%)$. The groups were compared in terms of sex, years, hospitals and most common diseases. In Table 1 the frequencies and chi-square results for these 1,826 patients by age groups, sex, years and hospitals are shown.

Table 1. Distribution of parameters by age groups

\begin{tabular}{|c|c|c|c|c|c|}
\hline & \multicolumn{3}{|c|}{ n (\%) } & \multirow{2}{*}{$\chi^{2}$} & \multirow{2}{*}{$p$} \\
\hline & 0-18 Years & 19-64 Years & +65 Years & & \\
\hline \multicolumn{6}{|l|}{ Sex } \\
\hline - Women & $195(41.8)$ & $235(46.0)$ & 559 (65.9) & $89.923(\mathrm{df}=2)$ & $.000^{* * *}$ \\
\hline - Men & $272(58.2)$ & $276(54.0)$ & $289(34.1)$ & & \\
\hline \multicolumn{6}{|l|}{ Years } \\
\hline - 2010-2012 & $30(6.4)$ & $89(17.4)$ & $77(9.1)$ & $164.344(\mathrm{df}=6)$ & $.000^{* * *}$ \\
\hline - 2013 & $12(2.6)$ & $62(12.1)$ & $71(8.4)$ & & \\
\hline - 2014 & $12(2.6)$ & $90(17.6)$ & $149(17.6)$ & & \\
\hline - 2015 & $413(88.4)$ & $270(52.8)$ & $551(65.0)$ & & \\
\hline \multicolumn{6}{|l|}{ Hospitals } \\
\hline - Gazi Yaşargil Edu. and Res. Hospital & $12(2.6)$ & $191(37.4)$ & $243(28.7)$ & $1,211.392(\mathrm{df}=6)$ & $.000^{* * *}$ \\
\hline - Diyarbakir Children Hospital & $315(67.5)$ & $0(0)$ & $0(0)$ & & \\
\hline - Selahaddin Eyyubi Public Hospital & $12(2.6)$ & $173(33.9)$ & 355 (41.9) & & \\
\hline - Hospitals in Districts & $128(24.7)$ & $147(28.8)$ & $250(29.5)$ & & \\
\hline \multicolumn{6}{|l|}{ Prevalance of diseases } \\
\hline - Neurodegenerative disorders & $240(51.4)$ & $331(64.8)$ & $362(42.7)$ & $44.823(\mathrm{df}=2)$ & $.000^{* * *}$ \\
\hline - Neurogenetic disorders & $141(30.2)$ & $73(14.3)$ & $80(9.4)$ & $97.800(\mathrm{df}=2)$ & $.000^{* * *}$ \\
\hline - Cardiovascular diseases & $12(2.6)$ & $40(7.8)$ & $195(23.0)$ & $127.117(\mathrm{df}=2)$ & $.000^{* * *}$ \\
\hline - Muskuloskeletal diseases & $31(6.6)$ & $32(6.3)$ & $100(11.8)$ & $16.037(\mathrm{df}=2)$ & $.000^{* * *}$ \\
\hline - Respiratory diseases & $24(5.1)$ & $21(4.1)$ & $61(7.2)$ & $6.054(\mathrm{df}=2)$ & $.048^{*}$ \\
\hline - Others & $19(4.1)$ & $14(2.7)$ & $50(5.9)$ & $7.651(\mathrm{df}=2)$ & $.022^{*}$ \\
\hline Total & $467(100)$ & $511(100)$ & $848(100)$ & & \\
\hline
\end{tabular}

As seen in Table 1, comparison of the three age groups by sex showed that there were more female patients in the age group 65 and over and male in 0-18 age group $\left(\chi^{2}=89.923\right.$, $p<.001)$. There was a significant difference when age groups were compared by year. In 2015, there was an increase in the use of services in all age groups $\left(\chi^{2}=164.344, p<.001\right)$. In Diyarbakir Children Hospital, use of home health care services were more widespread between 0-18 age group and the others were more efficient for other age groups, and this was statistically significant $\left(\chi^{2}=1,211.392, p<.001\right)$.

When the prevelance of the most common diseases were compared according to age groups, it was found that neurodegenerative diseases were more widespread in the age group 65 and over which was statistically significant $\left(\chi^{2}=44.823, p<.001\right)$.

Table 1 shows that the prevelance of neurogenetic dieases was larger in the $0-18$ age group $\left(\chi^{2}=97.800, p<.001\right)$. In the age group 65 and over musculoskeletal diseases $\left(\chi^{2}=16.037, p<.001\right)$ and respiratory diseases $\left(\chi^{2}=6.054\right.$, $p<.05)$ were more widespread.

As can be seen from Table 1, there was an increase in prevalence of other diseases in the age group 65 and over which was significant $\left(\chi^{2}=7.651, p<.05\right)$.

In Table 2, a statistical analysis was performed to compare years, diseases and hospitals by sex. Table 2 shows that there were no significant sex-based differences between years $\left(\chi^{2}=2.246, p>.05\right)$. A significant difference was found when utilization of hospitals were compared by sex; male patients utilized more Diyarbakir Children Hospital, and female patients utilized others $\left(\chi^{2}=28.610, p<.001\right)$.

A significant difference was found when the prevelance of common diseases were compared in terms of sex. Neurodegenerative diseases $\left(\chi^{2}=4.07, p<.05\right)$, neurogenetic diseases $\left(\chi^{2}=6.043, p<.05\right)$ and respiratory diseases $\left(\chi^{2}=5.254, p<.05\right)$ were more widespread in male patients, which was also found significant. When the prevelance of other diseases (cancer, diabetes, eye diseases and mental disorders) was compared, no significant results were 
found $\left(\chi^{2}=0.056, p>.05\right)$. Musculoskeletal $\left(\chi^{2}=17.943\right.$, A statistical analysis was performed to investigate the differ$p<.001)$ and cardiovascular diseases $\left(\chi^{2}=11.994, p<.001\right)$ ences between hospitals and prevelance of diseases by years. were seen more on female groups.

Results can be seen in Table 3.

Table 2. Sex based differences in the study parameters

\begin{tabular}{|c|c|c|c|c|}
\hline & \multicolumn{2}{|c|}{ n (\%) } & \multirow{2}{*}{$\chi^{2}$} & \multirow{2}{*}{$p$} \\
\hline & Women & Men & & \\
\hline \multicolumn{5}{|l|}{ Years } \\
\hline • 2010-2012 & $107(10.8)$ & $89(10.6)$ & $2.246(\mathrm{df}=3)$ & .523 \\
\hline • 2013 & $82(8.3)$ & $63(7.5)$ & & \\
\hline • 2014 & $145(14.7)$ & $106(12.7)$ & & \\
\hline • 2015 & $655(66.2)$ & $579(69.2)$ & & \\
\hline \multicolumn{5}{|l|}{ Hospitals } \\
\hline - Gazi Yaşargil Edu. and Res. Hospital & $250(25.3)$ & $196(23.4)$ & $28.610(\mathrm{df}=3)$ & $.000^{* * *}$ \\
\hline - Diyarbakir Children Hospital & $131(13.2)$ & $184(22.0)$ & & \\
\hline - Selahaddin Eyyubi Public Hospital & 325 (32.9) & 215 (25.7) & & \\
\hline - Hospitals in Districts & $283(28.6)$ & 242 (28.9) & & \\
\hline \multicolumn{5}{|l|}{ Prevalance of diseases } \\
\hline - Neurodegenerative disorders & $484(48.9)$ & $449(53.6)$ & $4.017(\mathrm{df}=1)$ & $.045^{*}$ \\
\hline - Neurogenetic disorders & $140(14.2)$ & $154(18.4)$ & $6.043(\mathrm{df}=1)$ & $.014^{*}$ \\
\hline - Cardiovascular diseases & $159(16.1)$ & $88(10.5)$ & $11.994(\mathrm{df}=1)$ & $.001^{* *}$ \\
\hline - Muskuloskeletal diseases & $114(11.5)$ & 49 (5.9) & $17.943(\mathrm{df}=1)$ & $.000^{* * *}$ \\
\hline - Respiratory diseases & $46(4.7)$ & $60(7.2)$ & $5.254(\mathrm{df}=1)$ & $.022^{*}$ \\
\hline - Others & $46(4.7)$ & $60(7.2)$ & $0.056(\mathrm{df}=1)$ & .814 \\
\hline Total & $989(100)$ & $837(100)$ & & \\
\hline
\end{tabular}

${ }^{*} p<.05 ;{ }^{* *} p<.01 ;{ }^{* * *} p<.001$

Table 3. Sex based differences in the study parameters

\begin{tabular}{|c|c|c|c|c|c|c|}
\hline & \multicolumn{4}{|c|}{ n (\%) } & \multirow{2}{*}{$\chi^{2}$} & \multirow[b]{2}{*}{$p$} \\
\hline & 2010-2012 & 2013 & 2014 & 2015 & & \\
\hline \multicolumn{7}{|l|}{ Hospitals } \\
\hline - Gazi yaşargil Education and Research Hospital & $57(29.1)$ & $59(40.7)$ & $97(38.6)$ & 233 (18.9) & $416.502(\mathrm{df}=9)$ & $.000^{* * *}$ \\
\hline - Diyarbakir Children's Disease Hospital & 0 & 0 & 0 & 315 (25.5) & & \\
\hline - Selahaddin Eyyubi Public Hospital & $95(48.5)$ & $68(46.9)$ & $136(54.2)$ & $241(19.5)$ & & \\
\hline - Hospitals in Districts & $44(22.4)$ & $18(12.4)$ & $18(7.2)$ & $445(36.1)$ & & \\
\hline \multicolumn{7}{|l|}{ Prevalance of diseases } \\
\hline - Neurodegenerative disorders & $126(64.3)$ & $89(61.4)$ & $154(61.4)$ & $564(45.7)$ & $58.237(\mathrm{df}=15)$ & $.000^{* * *}$ \\
\hline - Neurogenetic disorders & $29(14.8)$ & $16(11.0)$ & $24(9.6)$ & $225(18.2)$ & & \\
\hline - Cardiovascular diseases & $14(7.1)$ & 17 (11.7) & 37 (14.7) & 179 (14.5) & & \\
\hline - Muskuloskeletal diseases & $11(5.6)$ & $15(10.3)$ & $17(6.8)$ & $120(9.7)$ & & \\
\hline - Respiratory diseases & $7(3.6)$ & $5(3.4)$ & $14(5.6)$ & $80(6.5)$ & & \\
\hline - Others & $9(4.6)$ & $3(2.1)$ & $5(2.0)$ & $66(5.3)$ & & \\
\hline Total & $196(100)$ & $145(100)$ & $251(100)$ & $1,234(100)$ & & \\
\hline
\end{tabular}

Table 3 shows that, in 2014 and 2015, there was a signifi- $\left(\chi^{2}=58.237, p<.001\right)$.

cant increase in the use of home care health services in all of the hospitals when compared by years $\left(\chi^{2}=416.502\right.$, $p<.001)$. The comparison of the prevelance of the most common diseases according to years suggested that there was an increase in acquired brain injuries, respiratory diseases, cardiovascular diseases with respect to others

\section{Discussion}

When we compared age groups according to sex, we found a significant difference. In younger groups home health care services were utilized more by male patients. On the other hand, the use of home health care services was more 
spread among females in the older age groups. This finding was expected due to the longer life expectancy of women in Turkey. While this result was consistent with the findings of several previous studies, ${ }^{[12-15]}$ some other studies reported conflicting results. ${ }^{[16-19]}$

We found significant difference between years in terms of use of home health care services. In all age groups, 2015 was the most efficient year, because there was an increase in the use of home health care services in all age groups in this period. Since home health care services have begun to become compulsory in all public hospitals in recent years, it continued to become even more widespread last year. Our findings were consistent with other studies that reported home health care services were improving annually. ${ }^{[11,20,21]}$ District hospitals began to provide these services only one year ago; hence services in the city center hospitals are still more efficient.

There was significant difference when diseases were compared according to age groups. Neurological diseases were more often seen in the 19-64 age groupand among male patients. Our findings were consistent with several studies. ${ }^{[8,14,15,22-24]}$ Disabilities related to neurodegenerative disorders were more common in the youngest age group. When prevelance of cardiovascular diseases was compared, it was seen that, cardiovascular diseases were more widespread among older and female patient groups. While this finding was consistent with some studies, ${ }^{[17,25]}$ several other studies reported conflicting results. ${ }^{[12,26]}$ On the other hand prevelance of respiratory diseases was highest in older and male groups. This finding was incompatible with other studies that had found no significant difference between diseases by sex. ${ }^{[16,20]}$ However, the findings of the present study were compatible with those reported by other studies. ${ }^{[1,25]}$ This may result from higher rates of smoking and harder working conditions among males in Turkey.

There was a significant difference when musculoskeletal disorders were compared according to age and gender. They were more widespread in older and female patient groups, mostly due to Postmenopausal and post-traumatic ostoperosis, falls and fractures. Several previous studies found that women are likely to suffer more from musculoskeletal disorders. ${ }^{[12,25-27]}$ Our study is consistent with these studies.

\section{Conclusions}

Addressing chronic diseases among patients delivered home health care services is a very important issue for medical health care providers. Home health care services supplied by public or private health institutes has changed considerably over the last decade as chronic illnesses have increased in every age group due to chemicals, changes in food consumption and lack of physical activity. In our study, we saw that some specific diseases are more widespread among some age goups. There are more elderly patients among home care patients, and most of them are women. This is compatible with the studies reporting that the world is getting older and needs of elderly will be the main goal of health professionals in the future. As neurodegenerative diseases, musculoskeletal and respiratory diseases are more seen in the age group 65 and over, more specialists in these fields, especially physical therapists, will be required in the future.

Also, we found that prevelance of respiratory diseases was highest in older and male groups, and we commented that it result from higher rates of smoking and harder working conditions among males in Turkey. As this group of patients needs respiratory devices more, health staff must supply these devices readily. There are more female patients in the older groups and they may feel more uncomfortable and shy when male health staff help them; therefore more female health workers should take part in home care services.

Overall, as we classified diseases among home care patients, we believe that this classification will help to health proffesionals and health service suppliers in order to determine priorities.

\section{ETHICS STATEMENT}

This study was conducted according to the Helsinki Declaration. Ethics committee approval was obtained from Dicle University Hospital, Diyarbakır, Turkey. Data was provided from Ministry of Health and the Diyarbakır Directorate of Health Services, after receiving formal permission.

\section{CONFLicts OF INTEREST Disclosure}

The authors have no competing interests.

\section{REFERENCES}

[1] Ellenbecker CH, Samia L, Cushman MJ, et al. Patient Safety and Quality in Home Health Care. In:Hughes RG (Ed). Patient Safety and Quality: An Evidence-Based Handbook for Nurses. Chapter 13, Rockville (MD): Agency for Healthcare Research and Quality (US);
2008 [cited 2016 Jan 1]. Available from: http://www.ncbi.nlm .nih.gov/books/NBK2631/

[2] Aksoy H, Kahveci R, Şencan İ, et al. An overview of home care services and the current situation in Turkey. Turk Med J. 2015; 7(2): 162-168. 
[3] Home-based long-term care. World Health Organization technical report series no: 898, Geneva; 2000 [cited 2016 Jan 12] Available from: http://apps. who.int/iris/bitstream/1066 5/42343/1/WHO_TRS_898.pdf

[4] Kisa S. Turkish nurses' concerns about home health care in Turkey. Aust J Adv Nurs. 2008; 25(4): 97-106.

[5] Official Journal No: 25751. General Directorate of Development of Legislation and Publication. Implementation of Health Care Services at Home. 2005 [cited 2016 Feb 2]. Available from: http://www.mevzuat.gov.tr/Metin.Aspx?MevzuatK od=7 . 5.7542\& sourceXmlSear $\mathrm{ch}=\&$ MevzuatIliski $=0$

[6] The Ministry of Health. Directive on procedures and applications of home health care services. 2010 [cited 2016 Mar 5]. Available from: http://www.saglik.gov.tr/TR/dosya/1-72726 /h/son-yonerge.doc

[7] Anaby D, Hand C, Bradley L, et al. The effect of the environment on participation of children and youth with disabilities: a scoping review. Disability and Rehabilitation. 2013; 35(19): 1589-1598. http://dx.doi.org/10.3109/09638288.2012.748840

[8] Alford V, Ewen S, Webb G, et al. The use of the International Classification of Functioning, Disability and Health to understand the health and functioning experiences of people with chronic conditions from the person perspective: a systematic review. Disability and Rehabilitation. 2015; 37(8): 655-666. http://dx. doi .org/10.3109/096 38288.2014.935875

[9] Andrews J, Falkmer M, Girdler S. Community participation interventions for children and adolescents with a neurodevelopmental intellectual disability: a systematic review. Disability and Rehabilitation. 2015; 37(8): 825-833. http://dx.doi .org/10.3109/096 38288.2014 .944625

[10] Amiet C, Gourfinkel-An I, Bouzamondo A, et al. Epilepsy in Autism is Associated with Intellectual Disability and Gender: Evidence from a Meta-Analysis. Biological Psychiatry. 2008; 64: 577-582. http://dx.doi.org/10.1016/j.biopsych.2008.04.030

[11] Lafortune G, Balestat G. Trends in severe disability among elderly people: assessing the evidence in 12 OECD countries and the future implications. OECD Health Working Papers No. 26, OECD Publishing, Paris. 2007; 1-81.

[12] Al-Modeer MA, Hassanien NS, Jabloun CM. Profile of morbidity among elderly at home health care service in Southern Saudi Arabia. J Family Community Med. 2013; 20(1): 53-7. http://dx. doi.o $\mathrm{rg} / 10.4103 / 2230-8229.108187$

[13] Armstrong JJ, Zhu M, Hirdes JP, et al. Rehabilitation therapies for older clients of the Ontario home care system: regional variation and client-level predictors of service provision. Disability and Rehabilitation. 2015; 37(7): 625-631. http://dx. doi .org/10.3109/096 38288.2014.935494

[14] Brereton A, Tonge B, Einfeld S. Psychopathology in Children and Adolescents with Autism Compared to Young People with Intellectual Disability. Journal of Autism and Developmental Disorders. 2006; 36(7): 863-870. PMid: 16897401. http://dx.doi.org/10. $1007 /$ s $10803-006-0125-y$
[15] Maher CA, Toohey M, Ferguson M. Physical activity predicts quality of life and happiness in children and adolescents with cerebral palsy. Disability and Rehabilitation. 2016; 38: 865-869. http: //dx.doi.org/10.3109/09638288.2015.1066450

[16] Heinrich S, Luppa M, Matschinger H, et al. Service utilization and health-care costs in the advanced elderly. Value Health. 2008; 11(4): 611-20. http://dx.doi.org/10.1111/j.1524-4733.2007.0 0285. $\mathrm{x}$

[17] Hellström Y, Hallberg IR. Perspectives of elderly people receiving home help on health, care and quality of life. Health Soc Care Community. 2001; 9(2): 61-71.

[18] Liu LF, Tian WH, Yao HP. Utilization of health care services by elderly people with National Health Insurance in Taiwan: The heterogeneous health profile approach. Health Policy. 2012; 108(2-3): 246-55. http://dx.doi.org/10.1016/j . heal thpol .2012.08.022

[19] Maart S, Jelsma J. Disability and access to health care - a community based descriptive study. Disability and Rehabilitation. 2014; 36(18): 1489-1493. http://dx.doi.org/10.3109/09638288. 2013.807883

[20] Nadarevic-Stefanec V, Malatestinic D, Mataija-Redzovic A, et al. Patient satisfaction and quality in home health care of elderly islanders. Coll Antropol. 2011; 35(Supp 2): 213-16. PMid: 22220438.

[21] Thume E, Facchini LA, Tomasi E, et al. Home health care for the elderly: associated factors and characteristics of access and health care. Rev Saude Publica. 2010; 44(6): 1102-11. http://dx.doi.o $\mathrm{rg} / 10.3109 / 09638288.2015 .1099055$

[22] Etherington N, McDougall J, DeWit D, et al. Maternal factors and the emotional and behavioural functioning of adolescents with chronic health conditions. Disabil Rehabil. 2016; 38(14): 1356-1369. PMid: 26505557. http://dx.doi.org/10.3109/09638288.20 15.1099055

[23] Palisano RJ, Almarsi N, Chiarello LA, et al. Family needs of parents of children and youth with cerebral palsy. Child: Care, Health and Development. 2010; 36(1): 85-92. http://dx.doi.org/10.1111 $/ j .1365-2214.2009 .01030 . x$

[24] Sen E, Yurtsever S. Difficulties Experienced by Families With Disabled Children. Journal for Specialists in Pediatric Nursing. 2007; 12(4): 238-252. http://dx.doi.org/10.1111/j.1744-6155. 2007.00119.x

[25] Cornelius LR, Van der Klink JJL, De Boer M, et al. High prevalence of early onset mental disorders among long-term disability claimants. Disability and Rehabilitation. 2016; 38(6): 520-527. http://dx.doi.org/10.3109/09638288.2015.1046566

[26] Murtagh KN, Hubert MA, Hubert HB. Gender differences in physical disability among an elderly cohort. Am J Public Health. 2004; 94(8): 1406-11. PMid: 15284051. http://dx.doi.org/10.2105/AJPH . 94.8 .1406

[27] Doocy S, Adam S, Margarita T, et al. Chronic disease and disability among Iraqi populations displaced in Jordan and Syria. The International Journal of Health Planning and Management. 2013; 28(1): e1-e12. http://dx.doi.org/10.1002/hpm. 2119 